EESTI NSV TEADUSTE AKADEEMIA TOIMETISED. XVII KÖIDE KEEMIA * GEOLOOGIA. 1968, Nr. 2

ИЗВЕСТИЯ АКАДЕМИИ НАУК ЭСТОНСКОИ ССР. ТОМ ХVII

ХимИЯ * ГЕОЛОГИЯ. 1968, №2 2

М. ГУБЕРГРНЦ, Б. ТЯГУНОВ

\title{
ОПТИМАЛЬНЫЕ НАПРАВЛЕНИЯ В ЭНЕРГОХИМИЧЕСКОМ ИСПОЛЬЗОВАНИИ ПРОДУКТОВ ТЕРМИЧЕСКОГО РАЗЛОЖЕНИЯ СЛАНЦА С ТВЕРДЫМ ТЕПЛОНОСИТЕЛЕМ
}

Комплексное использование твердых топлив по энергохимическому принципу в крупном масштабе основано на сочетании их термической переработки с рациональным распределением получаемых -продуктов - в строгом соответствии с их свойствами, ценностью и потребностью народного хозяйства данного района страны в химическом сырье и облагороженном энерготопливе. Своеобразная природа прибалтийского сланца-кукерсита, характер распределения и специфический состав продуктов его термического разложения позволяют оценить этот каустобиолит как благодарное сырье для энергохимического использования [1, $\left.{ }^{2}\right]$.

Ценные потенциальные свойства сланца особенно проявляются при термической переработке его с твердым теллоносителем в температурных пределах процесса полукоксования. Одной из важных особенностей такого процесса является получение сравнительно широкой гаммы продуктов. Большую долю их, около $21 \%$ от пютенциального тепла суммы летучих, составляют газбензин и бензиновая фракция смолы. Около $17 \%$ от теплового потенциала заключено в газе полукоксования, для которого характерно высокое (до $70 \%$ по объему) содержание углеводородных компонентоз. Это позволяет варьировать распределение продуктов полукоксования между химическим и энергетическим звеньям в сравнительно широких пределах, Интенсивность нагрева и термического разложения топлива, высокая степень полезного использования его горючей части в этом процессе позволяют создать агрегаты с твердым теплоносителем такой мощности, какая требуется для выдачи большой массы продукции в условиях достаточно крупного энергохимического комплекса $\left[{ }^{2}\right]$.

При решении вопроса о рациональном распределении продуктюв полукоксования сланца между звеньями такого комплекса в условиях Северо-западного района европейской части СССР следует иметь в виду высокий уровень развития в нем промышленности и сельского хозяйства, большую плотность населения, отсутствие других местных ресурСов энерготоплива и растущую потребность района в электроэнергиі, топливе и химическом сырье.

В связи с этим необходимо рассмотреть несколько возможных и рациональных вариантов такого распределения, в которых были бы учтены не только отмеченные выше особенности технологического процесса, состав продуктов и принципиально возмсжные области их применения, но и сложившаяся конкретная конъюнктура в данном крупном экономическом районе. Такие варианты нами разработаны на основе результатов длительной эксплуатации опытно-промышленного агрегата 
с твердым теплоносителем при «смоляном» режиме $\left[{ }^{1,2}\right]$ и исследований процесса пиролиза сланцевых бензинов в опытной трубчатой печи [3].

Простейший первый вариант энергохимического комбинирования предполагает использование в химическом звене низших олефинов (этилена, пропилена, бутиленов) и дивинила, извлекаемых из газа полуксксования - всего около $11 \%$ от теплового потенциала системы. Остаточный высококалорийный газ (теплотворностью около $6500 \kappa \kappa a \Omega / \mathrm{m}^{3}$ ) и среднетяжелая часть смолы полукоксования, всего около $68 \%$ от потенциального тепла получаемых продуктов, представляют собой концентрированные малосернистые энерготоплива. Их применение должно резко улучшить эффективность производства электроэнергии в сравнении с непосредственным сжиганием такого «трудного» многозольного топлива, как сланец $\left[{ }^{2}\right]$. Смесь бензинов после необходимой очистки используется в качестве моторного топлива.

Достоинством такой схемы является относительная простота и отсутствие в ней звеньев дополнительного передела продуктов полукоксования. Существенный ее недостаток состоит в том, что из непосредственного использования в энергохимическом комплексе исключается до $21 \%$ от потенциальных ресурсов тепла, а отбор продуктов для энергетического звена сравнительно невысок. При дальнейшем рассмотрении других вариантов показатели первой схемы условно принимаются нами за $100 \%$. Такой методический прием позволит более наглядно, без загромождения излишним цифровым материалом, оценить особенности более «концентрированного» распределения сланцепродуктов в соответствии с поставленной задачей.

При этом во всех случаях нами не учитывается возможное вовлечение нескольких тысяч тонн фракции смолы с пределами кипения $150-250^{\circ} \mathrm{C}$ в химический передел для расширения производства синтетических моющих веществ в связи с незначительным, в сравнении с масштабом энергохимического комплекса, потреблением этого вида сырья. По той же причине не рассматриваются вопросы о потреблении пропана в качестве сжиженного газа, об использовании легких фенолсв и др.

Второй вариант предусмотрен для «граничного» случая конценграции производства исключительно в указанных выше двух направлениях, с доведением глубины отбора продуктов, иснользуемых в качестве химического сырья, до технологически обоснованного максимума (см. таблицу). Для этой цели в состав технологического звена термической переработки дополнительно включается пиролиз двух видов сырья: сланцевых бензинов и этан-пропановой фракции, получаемой в качестве побочного продукта при разделении газа для производства низших олефинов.

В итоге в качестве химического сырья в комплексе используются: олефины и дивинил из газа полукоксования и пирогазов (их количество возрастает примерно в два раза по сравнению с первым вариантом) и ароматизированный пиробензин - выкипающая до температуры $200^{\circ}$ фракция жидких продуктов пиролиза указанных видов сырья. В состав энерготоплив включаются: среднетяжелая часть смолы полукоксования в смеси с тяжелой фракцией жидких продуктов пиролиза, а также остаточные газы после выделения олефинов.

Глубина отбора химического сырья в этом варианте доводится до $24 \%$ от теплового потенциала системы и в 2,2 раза превышает аналогичный показатель для первой из рассматриваемых схем. Выработка энерготоплив возрастает на 16,5\%, причем выгодно изменяется их соот- 
Основные показатели вариантов комплексного энергохимического использования сланцепродуктов

\begin{tabular}{|c|c|c|c|c|}
\hline \multirow{2}{*}{ Показатели } & \multicolumn{4}{|c|}{ Варианты } \\
\hline & II & III & IV & V \\
\hline \multicolumn{5}{|l|}{$\begin{array}{l}\text { Выработка фактической продук- } \\
\text { цин *: }\end{array}$} \\
\hline энергомазут & 104 & 124,5 & 104 & 115 \\
\hline топлливный газ & 198 & 353 & 394 & 368 \\
\hline химическое сырье суммарное & 242 & 0,5 & 130 & 97 \\
\hline в т. ч. низшие олефины & 197 & - & 93,5 & 73 \\
\hline \multicolumn{5}{|l|}{$\begin{array}{l}\text { Выработка потенциального тепла } \\
\text { по виду продукции, в пересчеге }\end{array}$} \\
\hline $\begin{array}{l}\text { по виду продукции, в пересчете } \\
\text { на условное топливо *: }\end{array}$ & & & & \\
\hline энерготопливо суммарное & 116,4 & 148 & 132 & 138 \\
\hline химическое сырье суммарное & 220 & 0,5 & 108 & 90 \\
\hline \multicolumn{5}{|l|}{ Глубина отбора по теплу, в про- } \\
\hline топлив для әнергетики сы & & 99.5 & 87.0 & 92.5 \\
\hline для химического использования & 24,2 & 0,5 & 13,0 & 7,6 \\
\hline
\end{tabular}

* В процентах к показателям первого варианта (см. текст статьи).

ношение: количество газа увеличивается почти вдвое, а энергомазута на $4 \%$. В целом же уровень отбора потенциального тепла летучих для энергоиспользования повыщается примерно до 76\%. Это обеспечивает возможное увеличение производства электроэнергии без ввода дополнительных мощностей по добыче и переработке сланца, более чем на $17 \%$.

Такой комплекс в состоянии обеспечить сырьем группу химических предприятий большой мощности, характерных для промышленности органического синтеза на совремєнном этапе развития. Все же следует нметь в виду, что эти предприятия являются одновременно крупными потребителями электрической и тепловой энергии, особенно в звеньлх передела полимерных материалов. Конкретная обстановка в Северозападном районе не позволит, по-видимому, организовать такие энергоемкие производства в чересчур большом масштабе без наращивания энергетических мощностей и значительного увеличения капитальных вложений.

Третий вариант разработан для предельного случая, когда практически все продукты термического разложения сланца, пригодные для этой цели, используются в качестве энерготоплива. В топках электростанции полностью сжигается вся сырая смола, включая легкую фракцию, сырой газ полукоксования и газообразные продукты пиролиза газбензина (этот «первичный» продукт не может быть непосредственно использован в энергоагрегатах). Глубина отбора продуктов для энергетики в этом случае составляет $99,5 \%$ от потенциала, т. е. повышается на $48 \%$ по сравнению с первым и на $27 \%$ по сравнению со вторым вариантом. Количество топливного газа при этом возрастает соответственно в 3,5 и 1,75 раза, а жидкого энерготоплива - всего на 24,5 или на 19\%. Для химических целей используется лишь небольшое количество пиробензина, на основе которого организовать самостоятельное химическое производство не представляется возможным.

Такая схема может быть реализована лишь в период освоения энергохимического принципа - при эксплуатации первой очереди гипотетического комбината; дальнейшее развитие пронзводства в указанном 
техническом направлении неизбежно окажется связанным с химическим использованием такого ценного сырья, как олефиновые и ароматические углеводороды.

Четвертый вариант является промежуточным. В нем предусматрнвается тот же технологический цикл, что и во втором, т. е. организация пиролиза бензинов и рецикла этан-пропана. В качестве же химического сырья отбору подлежат только продукты пиролиза - олефины и пиробензин. Глубина такого отбора достигает примерно $13 \%$ от потенциала. В энергетическое звено направляются обычный (см. второй вариант) энергомазут, сырой газ полукоксования и остаточный газ из цикла пиролиза. Энергетическая эффективность, определяемая количеством условного топлива, возрастает по сравнению с первым вариантом на $32 \%$ и по сравнению со вторым - на $13 \%$ и эквивалентна $89 \%$ от потребления энерготоплив при максимальном энергетическом использовании системы. Однако структура энерготоплив здесь более выгодна, чем во всех предыдущих случаях: количество топливного газа (в пересчете на неизменную его теплотворность) возрастает в 3,9 раза по сравнению с первым вариантом и, естественно, превышает соответствующий показатель для третьего варианта. Соответствующее повышение эффективности энергозвена нами в таблице не учитывается.

Другое достоннство этого варианта заключается в использовании концентрированного сырья для извлечения олефинов, так как содержание их в пирогазе достигает $45 \%$ против $35 \%$ в газе полукоксования $\left[{ }^{1-3}\right]$ при неизменно большом объеме выработки ароматизированного пиробензина. Масштаб производства низших олефинов в таком варнанте вполне достаточен для организации соответствующих предприятий хнмического синтеза, но рассчитан на снижение энергозатрат на собственные нужды более чем вдвое в сравнении со вторым вариантом.

При разработке пятого варианта учтена не только возрастающая потребность народного хозяйства района в электроэнергии, но и целесоббразность кооперирования энергохимического комплекса с реконструируемыми действующими сланцехимическими предприятиями.

В схеме предусматривается организация пиролиза газбензина и части бензиновой фракции, выкипающей до температуры $150^{\circ}$, в смеси с аналогичными продуктами из реконструируемого предприятия (замена части действующих агрегатов установками с твердым теплоносителем). Для химического использования по-прежнему выделяются лишь олефины и легкая часть жидких продуктов из звена пиролиза. В итоге глубина отбора продуктов для хнмического звена составляет $7 \%$ от потенциала, но объем производства химического сырья обеспечивает сооружение самостоятельных предприятий для его передела.

Сравнительная энергетическая эффективность комплекса возрастает по сравнению с показателями первой, второй и четвертой вариантных схем, а условия работы энергоагрегатов существенно облегчаются в сравнении с третьей схемой, поскольку в энергетику направляется мазут с началом кипения при $150^{\circ}$. Структура энерготоплив в этом случае также более благоприятна.

В дополнение к приведенным материалам укажем, что перечисленными схемами, конечно, не исчерпываются все возможные варианты комбинирования химии и энергетики на технической базе термической переработки сланца с твердым теплоносителем. В частности, нами рассмотрен случай кооперации энергохияического комбината с действующими предприятиями лишь при частичной, далеко не полной реконструкции последних. Более широкое внедрение метода переработки сланца 
с твердым теплоносителем в практику работы существующих предприятий может создать еще более благоприятные условия для рационального распределения сланцепродуктов в масштабе Советской Прибалтики и Ленинградской области. Все же эти схемы могут служить основой для разработки обоснованных технико-экономических прогнозов. В одном из случаев (второй вариант в несколько усложненном виде) такой прогноз был разработан [2] и дал положительные результаты.

Анализ приведенных материалов позволяет также выявить объективные преимущества (чисто технического характера) сланцепереработки в энергохимическом комплексе по сравнению с производствоп того же сырья в нефтехимии.

Первое из этих преимуществ заключается в необычной глубине огбора химического сырья без ущерба для качества остальных целевых (топливных) продуктов. В нефтеперерабатывающей промышленносги этот показатель, при соблюдении того же условия, находится на несравненно более низком уровне. Далее, специфичным для кукерсита и продуктов его переработки является высокий «потенциал ароматизации». Доля ароматических углеводородов из пиробензина от суммарного вырабатываемого химического сырья в третьем и четвертом вариантах составляет примерно $33 \%$ по теплу. Напомним, что спрос на ароматические углеводороды в Советском Союзе на протяжении ряда лет будет непрерывно возрастать, а производство их в нефтехимии технически сложно и связано с получением большого количества отхюдов. С этой точки зрения оптимальными являются второй, четвертый и пятый варианты.

В заключение подчеркнем, что применение энергохимического приіципа и нового метода термической переработки твердого топлива в сочетании с пиролизом части получаемых продуктов открывает перед. отечественной сланцехимической промышленностью перспективу широкого производства принципиально новых видов химического сырья.

\section{Л И Т Е Р Т У Р А}

1. Губергриц М. Я., Бродская Б. Х., Галынкер И. С., Куйв К. А., Л аус Т. Н., Маргусте М. А., Мильк А. А., Па альме Л. П., Степанов И. И., Тягунов Б. И., Эленурм А. А., Термическая переработка сланца-кукерсита, «Валгус», Таллин, 1966.

2. Galynker I. S., Tiagunov B. I., Hubergritz M. E., Chicul V. I., Smirnov A. S., World Power Conference, Tokyo Sectional Meeting 16-20 October 1966, Paper 161, II B, USSR.

3. Губергриц М. Я., Мильк А. А., Аранович Ю. В., Волль М. А., Дойлов С. К., Степ нов А. В., Степ нов И. И., Химия твердого топлива, № 3,75 (1967).

Ннститут химии Академии наук Эстонской ССР Энергетический институт и.. Г. М. Кржижановского
Поступила в редакцию 2/II 1968 


\section{TAHKE SOOJUSEKANDJA MEETODIL LAGUNDATUD PÕLEVKIVIPRODUKTIDE ENERGOKEEMILISE KASUTAMISE OPTIMAALSED SUUNAD}

Artiklis esitatakse tahke soojusekandjaga töötlemisel saadavate pōlevkiviproduktide energokeemilise kasutamise ratsionaalseid variante, arvestades toodangu võimalikku tarbimist NSV Liidu Looderajoonis.

Energeetilise kütuse saamist suuremal hulgal (ligikaudu $24 \%$ lenduvate produktide potentsiaalsest soojusest) nähakse ette II variandi rakendamisega (vt. tabel). Maksimaalses koguses (99,5\% potentsiaalsest soojusest) võimaldab energokeemilist toorainet saada variant III. Põlevkiviproduktide keemilise kasutamise aste variantide IV ja V korral on vastavalt 13 ja $7,5 \%$ potentsiaalsest soojusest.

\section{GUBERGRITS, B. TYAGUNOV}

\section{THE UTILIZATION OF OIL SHALE PROCESSING PRODUCTS IN POWER AND CHEMICAL INDUSTRY}

Some aspects of the oil shale thermal decomposition products (on the basis of solid-solid technics) distribution and their utilization in power and chemical industry are discussed. The highest possible extent of the chemical utilization of oil shale products is considered to reach about 24 per cent of the total amount of potential heat (see variant II of the Table). The maximum amount of fuel for power generation (99.5 per cent of the heat potential) is provided by variant III, the intermediate alternatives corresponding to the variants IV and V (the extent of the chemical utilization being 13 and 7.5 per cent of the total potential heat consumption). 